\title{
Time-related mortality for women after coronary artery bypass graft surgery: A population-based study
}

\author{
Veena Guru, MD $D^{\mathrm{a}, \mathrm{b}}$ \\ Stephen E. Fremes, MD, MSc ${ }^{a, b}$ \\ Jack V. Tu, MD, PhD ${ }^{a, c}$
}

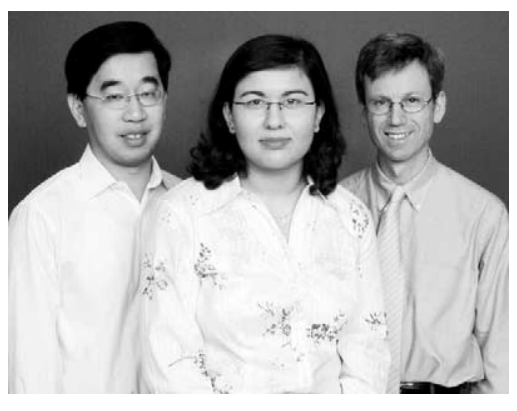

From the Institute for Clinical Evaluative Sciences $^{\mathrm{a}}$ and the Divisions of Cardiovascular Surgery ${ }^{\mathrm{b}}$ and General Internal Medicine, ${ }^{\mathrm{c}}$ Sunnybrook and Women's College Health Sciences Centre, Toronto, Ontario, Canada.

This study was performed in cooperation with the Cardiac Care Network of Ontario.

Dr Guru is supported by a salary fellowship for the Canadian Institutes of Health Research (CIHR) and a grant from the TannaSchulich fellowship fund of Sunnybrook and Women's College Health Sciences Centre. Dr Tu is supported by a Canada Research Chair in Health Services Research and through a grant for the Canadian Cardiovascular Outcomes Research Team (www.ccort.ca) from the CIHR and the Heart and Stroke Foundation of Canada.

Read in part at the 56th annual Canadian Cardiovascular Congress, Toronto, Ontario, Canada, October 24-29, 2003, and the American Heart Association Scientific Sessions 2003, Orlando, Fla, November 9-12, 2003.

Received for publication Sept 10, 2003; revisions requested Dec 1, 2003; accepted for publication Dec 9, 2003.

Address for reprints: Veena Guru, MD, Institute for Clinical Evaluative Sciences, 2075 Bayview Ave, G106, Toronto, Ontario M4N 3M5, Canada (E-mail: veena.guru@utoronto.ca).

J Thorac Cardiovasc Surg 2004;127:1158-65

$0022-5223 / \$ 30.00$

Copyright (C) 2004 by The American Association for Thoracic Surgery

doi:10.1016/j.jtcvs.2003.12.008
Objective: This study explores the relative early and late mortality risks in women and men after coronary artery bypass graft surgery.

Methods: This was a retrospective cohort study $(\mathrm{n}=54,425$ patients, 12,079 women) using clinical data for all patients who underwent isolated coronary artery bypass graft surgery in Ontario between fiscal years 1991 and 1999 obtained from the Cardiac Care Network database, with outcomes of early ( $\leq 1$ year) and late $(>1$ year up to 10 years) interval mortality identified through linkage to administrative databases.

Results: Female surgical candidates were older $(65$ vs 62 years, $P<.0001)$ and higher-risk patients. The risk-adjusted survival of female patients was worse than that of male patients in the first year after coronary artery bypass graft surgery, but their long-term mortality was similar to that of male patients. The Cox proportional hazards model for early mortality had an adjusted female hazard ratio of 1.44 (95\% confidence interval, 1.29-1.61; $P=.02$ ). This significantly differed from the late mortality model, which had a hazard ratio of 0.89 (95\% confidence interval, $0.78-1.0 ; P=.06)$.

Conclusions: Early mortality was significantly higher for women after coronary artery bypass graft surgery, despite adjustment for confounding factors. However, the long-term relative mortality risk for women appeared equivalent to or even better than that experienced by men as early as 1 year after coronary artery bypass graft surgery. This population-based study of long-term mortality supports the benefits of coronary artery bypass graft surgery for women in the current era. However, further research is needed to identify ways to reduce early postoperative mortality in women.

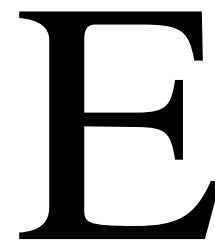

arly mortality (in-hospital or 30-day mortality) for women after coronary artery bypass graft (CABG) surgery has been shown to be greater than that of men. ${ }^{1-6}$ However, some conflicting studies report that early mortality among women is equivalent to that among men. ${ }^{4,6-9}$ Published odds for early mortality among female patients have ranged between 1 to 2.5 times that experienced by male patients. ${ }^{1-6,10}$ The majority of these studies have been retrospective in nature, most from single institutions. ${ }^{4,6-8,10-15}$ There is some evidence to suggest that with improved surgical techniques in the current era, the early mortality gap between men and women is narrowing. ${ }^{16}$

This difference in mortality has been explained by the fact that female CABG surgery candidates frequently present with older age, smaller body size, smaller coronary arteries, more urgent status, and more comorbid factors than their male counterparts. ${ }^{1,2,9,11,17}$ The difference in outcomes experienced by women after CABG surgery could also be related to delayed referral or a different pathogenesis of the progression in coronary atherosclerosis. ${ }^{8,18,19}$ It is also not clear whether graft 
patency is worse for female patients. ${ }^{12,20}$ It is known that women are less likely to receive internal thoracic artery (ITA) grafts because of small ITA size, as well as concerns with sternal healing. ${ }^{2,6}$ Women are less likely to receive complete revascularization, and this might be in part because of their smaller coronary artery size and pattern of disease. ${ }^{6}$ This all greatly affects their early mortality, even with extensive risk adjustment, and likely also has a significant effect on their late mortality after CABG surgery.

There is less known about the long-term result after coronary surgery in women. There is some evidence to suggest that between 5 and 6 years after CABG surgery, the results are the same or might be better for female patients, with odds ratios (ORs) for late death of between 0.4 and 1 as compared to male patients. ${ }^{7,10,14,15,21-23}$ This is demonstrated by a population-based study from the city of Stockholm in Sweden involving 2 institutions with 607 women and 3326 men, which revealed the 5-year mortality risk to be equivalent between sexes for patients operated on between 1980 and 1989. ${ }^{15}$ The reason behind the trend toward improved long-term survival for women compared with men is not known. It might simply be a result of the fact that women have a later onset of their cardiovascular disease and survive longer in the general population. The original studies that demonstrated the long-term benefits of CABG surgery, namely the Coronary Artery Surgery Study and Bypass Angioplasty Revascularization Investigation had only a minority of women. These studies were conducted in a previous era with highly selected patients who are not representative of the current population of patients undergoing CABG. Unfortunately, the evidence behind the longterm survival benefits of CABG surgery for women is not as robust as it is for men. ${ }^{1,22}$

The purpose of this study is to evaluate mortality between women and men both early and late after CABG surgery by using large population-based clinical and administrative databases in the province of Ontario.

\section{Methods}

\section{Study Population}

This was a retrospective cohort study ( $\mathrm{n}=54,425$ patients) of all patients who underwent isolated CABG surgery (without concomitant valve surgery) in Ontario between September 1, 1991, and March 31, 2000, obtained from the Cardiac Care Network (CCN) of the Ontario database. The CCN data are collected by nurses for waiting list management of patients for cardiac surgery in the province of Ontario according to their clinical characteristics. There is a biannual chart audit of the $\mathrm{CCN}$ database with a data accuracy rate of greater than $95 \%$. The core covariates recognized in the literature for risk adjustment of mortality are available through this database. ${ }^{24}$

\section{Data Linkage}

The patients were linked to 3 administrative databases for further clinical information by using unique encrypted identifiers, such as in-hospital and out-of-hospital death. The 3 databases included the Canadian Institute for Health Information database, the Registered Persons Database, and the Ontario Health Insurance Plan database. The Registered Persons Database registers the deaths of all persons residing in Ontario and has been validated against the Canadian Institute for Health Information database for in-hospital deaths. The Ontario Health Insurance Plan database includes the claims submitted by all cardiac surgeons for reimbursement for provided services. Socioeconomic status was determined from linkage of the postal code of each patient (Enumeration Area) to the $1996 \mathrm{Ca}-$ nadian Census database by which each patient's income quintile is designated on the basis of their primary residence. For patients who did not have a Canadian postal code listed, these data were not available. Data for 1991 were only available from September 1 onward but otherwise were analyzed on a fiscal year basis (April 1 of the year to March 31 of the subsequent year).

\section{Data Analysis}

Separate prediction models for male and female sex and early and late mortality were constructed to identify any obvious covariate interactions. The primary outcomes assessed included early interval mortality (30 days to 1 year) and late interval mortality at different time points ( $>1$ year to 10 years). A Kaplan-Meier curve was constructed by sex for the entire cohort to describe mortality after CABG surgery. A Kaplan-Meier curve was also constructed by sex for comparison with an age-matched sample of the general population.

Cox proportional hazards models were used to adjust mortality for men and women for the entire cohort by using tailored risk adjustment with previously validated variables. ${ }^{24,25}$ The variables included in the risk adjustment models were as follows: age, Charlson comorbidity score, urgency status, previous CABG surgery, congestive heart failure, left ventricular grade, era of operation, recent preoperative myocardial infarction, previous CABG surgery, history of preoperative stroke, peripheral vascular disease, and surgical coronary artery anatomy. The assumption of proportionality for Cox hazards analysis was tested by using a sex versus duration to death or follow-up time covariate. Because this assumption was violated, separate early mortality ( $\leq 1$ year) and late mortality ( $>1$ year) Cox models were created. The late mortality model was created on the cohort described, excluding those patients who died before or at 1 year after the operation. Other variables added to the risk-adjustment model included use of an ITA, socioeconomic status (available for $\mathrm{n}=53,702$ ), and body surface area (BSA; available for subgroup of cohort [1998-1999], $\mathrm{n}=13,921)$. Risk-adjusted survival curves were constructed by sex.

Stepwise logistic regression models were developed to determine the risk-adjusted OR for female interval mortality at various time points ( 30 days, 31 days to 1 year, $>1$ year to 2 years, $>2$ years to 4 years, $>4$ years to 8 years, and $>8$ years to 10 years) by using subgroups of patients who survived to this time point and who had similar follow-up, depending on their operative date. Through this method, we were able to isolate the time point at which the mortality risk for female sex changed from the early to late time periods after the operation. Lack-of-fit statistics were optimized for all logistic models constructed, including the $\mathrm{c}$ statistic (area under the receiver operator curve) and the Hosmer- 


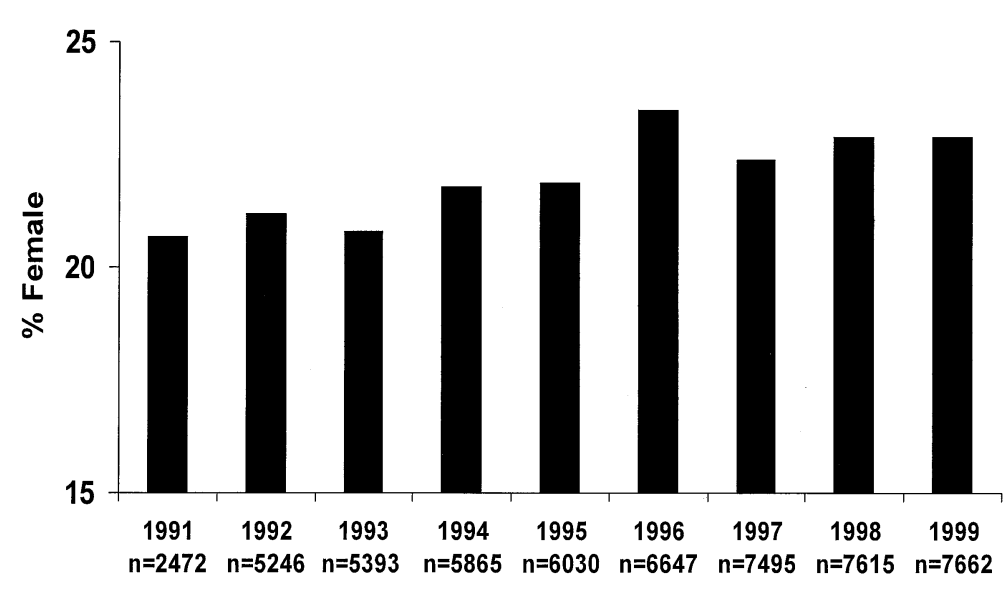

Fiscal Year

Figure 1. Percentage of female patients undergoing isolated CABG surgery in Ontario by fiscal year (1991-1999).

Lemeshow statistic, for adequate discrimination and calibration of the models. The c statistic is as follows for each logistic mortality model: 30 days, $0.78 ; 1$ year, $0.77 ; 2$ years, $0.70 ; 4$ years, $0.69 ; 8$ years, 0.71; and 10 years, 0.72 . The adjusted 30 -day death rates for each sex by fiscal year, left ventricular grade, triage status, Canadian Cardiovascular Society (CCS) angina class, and age were also analyzed. These adjusted mortality rates (in percentages) were calculated by multiplying the observed to expected death ratio by the average death rate in the cohort for various subgroups. The expected death was calculated by using 30-day mortality logistic regression models (excluding the variable being compared). The statistical analyses were completed with SAS software (version 8.2; SAS Institute Inc, Cary, NC).

\section{Results}

\section{Patient Population}

A total of 54,425 patients were operated on during the study period, including 12,079 (22\%) female patients and 42,246 (78\%) male patients. The proportion of female patients undergoing CABG surgery increased slightly from $21 \%$ in 1991 to $23 \%$ in $1999(P<.01$, Figure 1). Compared with men, women were older and more likely to possess a comorbid condition (Table 1) ${ }^{26}$ Women were more likely to present with congestive heart failure, urgent or emergency triage status, Canadian Cardiovascular Angina class III or IV, or a recent myocardial infarction (Table 1). Female patients had a lower proportion of surgically significant coronary artery disease compared with male patients (Table 1). Female patients were less likely (70\%) then male patients to receive at least one arterial bypass (79\%).

\section{Early Results}

The crude 30-day mortality rates of female patients were higher compared with those of male patients regardless of the year in which the operation was completed, and this difference remained true with risk adjustment (Figures 2 and 3). However, both the crude and risk-adjusted 30-day mortalities decreased over time for both sexes (Figures 2 and 3). For female patients, the risk-adjusted 30-day mortality decreased from $4.7 \%$ in 1991 to $2.1 \%$ in 1999 . For male patients, the risk-adjusted 30-day mortality decreased from $4.1 \%$ in 1991 to $1.7 \%$ in 1999. Risk-adjusted 30-day mortality by sex and high-risk subgroups, including age, CCS angina class, and left ventricular grade, demonstrated a higher mortality in women in all categories. The largest gaps in mortalities between sexes were for women aged 80 years or older with CCS class $4 \mathrm{c}$ angina (defined as unstable angina with symptoms refractory to treatment or hemodynamic instability) or left ventricular grade 3 or 4 (Table 2). These data show that the risk-adjusted 30-day mortality for women has remained higher than that for men in our cohort.

\section{Late Results}

The Kaplan-Meier crude survival curve showed that female patients had a worse early and late survival after CABG surgery (Figure 4). The survival curves of a random sample of age-matched Ontario residents by sex during the same time period demonstrated that women have an improved long-term survival compared with that of men (Figure 4). It is important to note that this survival curve from the general population is not risk adjusted to the CABG surgery cohort.

The risk-adjusted survival curve demonstrated that the absolute survival rate for men and women became equivalent at 4 years after the operation, as seen by the overlapping curves at this time point (Figure 5). Two Cox proportional hazard models were constructed for 2 separate cohorts defined by whether death occurred in the interval from 0 to 365 days after the operation inclusive (female hazard ratio [HR], 1.44; 95\% confidence interval [CI], 1.29-1.61; $P=$ .02 ) or if death occurred after 365 days (female HR, 0.89; 


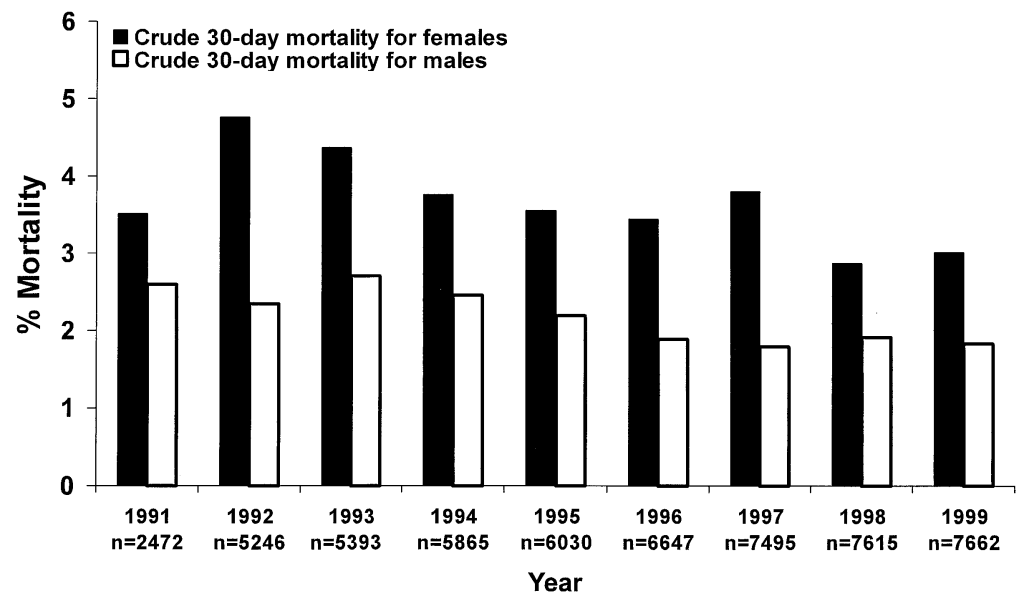

Figure 2. Crude 30-day mortalities for patients undergoing isolated CABG surgery in Ontario (1991-1999) by sex and fiscal year.

TABLE 1. Clinical characteristics of patients undergoing CABG surgery in Ontario in the years 1991 through 1999 ( $n=$ 54,425)

\begin{tabular}{|c|c|c|c|}
\hline & Male patients $(n=42,246)$ & Female patients $(n=12,079)$ & $P$ value \\
\hline Age $(y)$ & $62 \pm 10$ & $65 \pm 9$ & $<.0001$ \\
\hline Charlson comorbidity score & $0.73 \pm 0.9$ & $0.83 \pm 0.95$ & $<.0001$ \\
\hline Chronic obstructive pulmonary disease & $8.0 \%$ & $8.8 \%$ & .003 \\
\hline Cerebrovascular disease & $6.4 \%$ & $8.2 \%$ & $<.0001$ \\
\hline Diabetes & $21.4 \%$ & $29.3 \%$ & $<.0001$ \\
\hline Dialysis & $0.7 \%$ & $0.9 \%$ & $<.0001$ \\
\hline Peripheral vascular disease & $8.0 \%$ & $9.1 \%$ & $<.0001$ \\
\hline Congestive heart failure & $8.3 \%$ & $12.5 \%$ & $<.0001$ \\
\hline Urgent or emergency triage status & $46.8 \%$ & $53.6 \%$ & $<.0001$ \\
\hline Canadian Cardiovascular Class III or IV & $80.5 \%$ & $88.5 \%$ & $<.0001$ \\
\hline Recent myocardial infarction (within $30 \mathrm{~d}$ ) & $15.3 \%$ & $18.1 \%$ & $<.0001$ \\
\hline Left main coronary artery disease & $17.9 \%$ & $16.7 \%$ & .003 \\
\hline Significant coronary artery disease ${ }^{*}$ & $82.0 \%$ & $78.0 \%$ & $<.0001$ \\
\hline Grade 3 or 4 left ventricular grade & $23.7 \%$ & $18.9 \%$ & $<.0001$ \\
\hline Previous CABG surgery & $5.5 \%$ & $2.8 \%$ & $<.0001$ \\
\hline
\end{tabular}

The Charlson comorbidity score was calculated as previously described. ${ }^{26}$ CABG, Coronary artery bypass graft.

Canadian Cardiovascular Class III angina is defined as patients with a marked limitation of their ordinary physical activity caused by angina. Canadian Cardiovascular Class IV angina includes all patients admitted to the hospital with unstable angina.

* Significant coronary artery disease is defined by either left main, 2-vessel coronary artery disease with left anterior descending artery disease or triple-vessel coronary artery disease.

95\% CI, $0.78-1.02 ; P=.06)$ to determine the different risks in these different time intervals. Thus, female sex conferred an increased risk of death within the first year following surgery and no longer was predictive of death at beyond 1 year after the operation.

This was confirmed and further described through riskadjusted ORs by using logistic regression for interval mortality at various time points (Figure 6). It was found that the 30-day mortality of female patients was greater than that of male patients (OR, 1.45; 95\% CI, 1.23-1.63; $P<.01)$. This negative effect of female sex on mortality risk became equivalent to that of male sex from 1 year on after $\mathrm{CABG}$ surgery as follows: greater than 30 days to 1 year (OR, 0.96; $95 \% \mathrm{CI}, 0.82-1.11 ; P=.57$ ), greater than 1 to 2 years (OR, $0.90 ; 95 \% \mathrm{CI}, 0.76-1.07 ; P=.25)$, greater than 2 to 4 years (OR, $0.89 ; 95 \% \mathrm{CI}, 0.78-1.02 ; P=.10$ ), greater than 4 to 8 years $(\mathrm{OR}, 0.91 ; 95 \% \mathrm{CI}, 0.78-1.07 ; P=.27)$, and greater than 8 to 10 years $(\mathrm{OR}, 0.91 ; 95 \% \mathrm{CI}, 0.63-1.32 ; P=.62)$ . This sensitivity analysis confirmed the results of the above Cox model.

Further risk-adjustment factors were added to the early and late Cox models to understand their effects on sexbased mortality. Income quintile adjustment decreased the 1-year mortality risk of female sex to an HR of 1.19 (95\% 


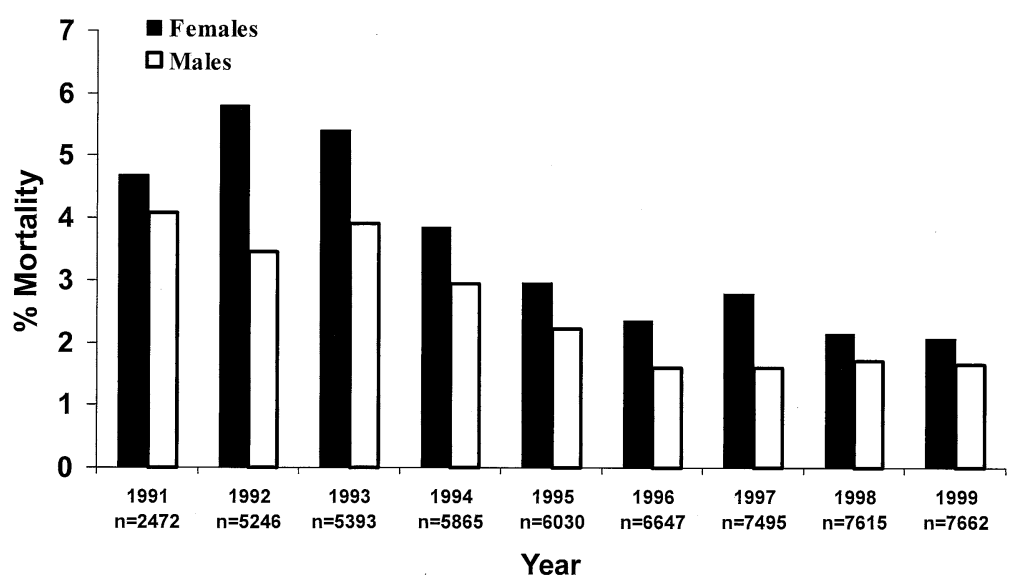

Figure 3. Risk-adjusted 30-day mortalities for patients undergoing isolated CABG surgery in Ontario (1991-1999) by sex and fiscal year.

TABLE 2. Risk-adjusted 30-day mortality after CABG surgery in Ontario from 1991 through 1999 by sex for high-risk subgroups $(n=54,425)$

\begin{tabular}{lcc}
\hline & $\begin{array}{c}\text { Male patients } \\
(\mathbf{n}=\mathbf{4 2 , 2 4 6 )}\end{array}$ & $\begin{array}{c}\text { Female patients } \\
(\mathbf{n}=\mathbf{1 2 , 0 7 9 )}\end{array}$ \\
\hline Age $<50 \mathrm{y}$ & $0.50(0.29-0.70)$ & $0.79(0.34-1.24)$ \\
Age $50-59$ y & $0.83(0.66-1.01)$ & $1.42(1.05-1.79)$ \\
Age 60-69 y & $1.81(1.60-2.03)$ & $2.55(2.17-2.94)$ \\
Age 70-79 y & $5.83(5.34-6.31)$ & $7.03(6.30-7.75)$ \\
Age $\geq 80$ y & $9.55(6.87-12.24)$ & $17.59(13.85-21.33)$ \\
Left ventricular & $1.43(1.29-1.57)$ & $2.08(1.86-2.30)$ \\
grade 1 or 2 & & \\
Left ventricular & $5.64(5.17-6.12)$ & $7.00(6.14-7.87)$ \\
grade 3 or 4 & & \\
Elective & $1.19(1.03-1.34)$ & $1.90(1.61-2.18)$ \\
Urgent or & $3.38(3.12-3.64)$ & $4.39(3.97-4.81)$ \\
emergency & & \\
triage status & & $1.30(0.85-1.74)$ \\
CCS class 1 or 2 & $0.71(0.52-0.90)$ & $1.93(1.57-2.28)$ \\
CCS class 3 & $1.24(1.06-1.42)$ & $3.53(2.89-4.17)$ \\
CCS class 4a & $2.77(2.38-3.15)$ & $3.75(3.11-4.38)$ \\
CCS class 4b & $2.75(2.35-3.15)$ & $9.46(8.18-10.75)$ \\
CCS class 4c & $7.02(6.18-7.86)$ &
\end{tabular}

Values are presented as percentages (95\% confidence intervals).

The adjusted mortality rates in this table were calculated by multiplying the observed to expected death ratio by the average death rate in the cohort for various subgroups. Expected death was calculated by using 30-day mortality logistic regression models (excluding the variable being compared).

$C A B G$, Coronary artery bypass graft. CCS, Canadian Cardiovascular Society angina class. CCS class 1 or 2 includes patients who are either asymptomatic or experience a slight limitation of their ordinary activity caused by angina. CCS class 3 includes patients with a marked limitation of their ordinary physical activity caused by angina. CCS Class 4a includes all patients admitted with unstable angina who become pain free with medical therapy. CCS Class $4 \mathrm{~b}$ includes all patients admitted with unstable angina who experience pain with minimal activity despite aggressive medical therapy. CCS Class 4c includes all patients admitted with unstable angina who require intravenous treatment or intra-aortic balloon pump insertion to alleviate anginal symptoms or to maintain hemodynamic stability.
CI, 1.08-1.31; $P<.001)$. Female sex risk for late mortality was significantly lower than male sex risk after adjustment for income quintile (HR, 0.94; 95\% CI, 0.884-0.998; $P=$ $.04)$. ITA use was a significant predictor of both early survival (HR, 0.64; 95\% CI, 0.59-0.70; $P<.0001)$ and late survival (HR, 0.79; 95\% CI, 0.74-0.83; $P<.0001$ ) but did not change the female sex risk on mortality. BSA data were available in a limited available sample of patients $(\mathrm{n}=$ 13,921, with 3172 female patients). Adjustment for BSA eliminated female sex as a risk factor for 30-day mortality (HR, 1.04; 95\% CI, 0.84-1.30; $P=.72$ ) but did not change the late $(>1$ to 10 years) mortality risk for female patients (HR, 1.05; 95\% CI, 0.83-1.31; $P=.70$ ). These additional variables used in adjustment in subcohorts were able to eliminate female sex as a predictor of early mortality.

\section{Discussion}

We performed a retrospective population-based study of patients undergoing isolated CABG surgery in Ontario between 1991 and 1999 that provides insights regarding postoperative time-dependent mortality for female patients compared with male patients.

Women tend to be higher-risk operative candidates, and this difference in mortality is larger for those female patients who were elderly or had unstable symptoms. The risk-adjusted OR for mortality among female patients is no different than one at 1 year after CABG surgery and remains this way until 10 years after the operation. At 4 years after the operation, the absolute mortality rate for female patients becomes similar to that for male patients, as seen by overlapping risk-adjusted survival curves (Figure 4). The crude survival for both sexes after CABG surgery was worse than that of the age-matched general population. Female patients undergoing $\mathrm{CABG}$ had a much larger disparity than their male counterparts to age-matched control subjects both for early and late crude survival. 


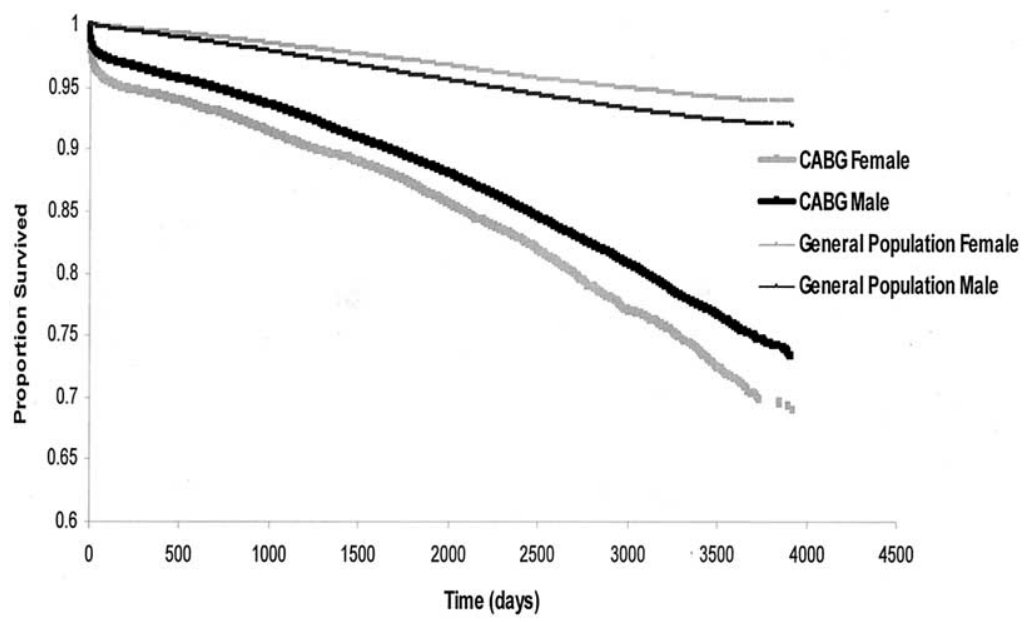

Figure 4. Crude survival curve by sex of patients undergoing isolated CABG surgery and age-matched control subjects in the general population in Ontario (1991-1999). A random sample of Ontario residents (comprised of 100,000 men and 100,000 women) alive between 1991 and 1999 was selected from the Registered Persons Database with the same age and sex distribution as observed in the CABG surgery cohort of this study. The Registered Persons Database contains information on all persons in Ontario possessing a valid health card number.

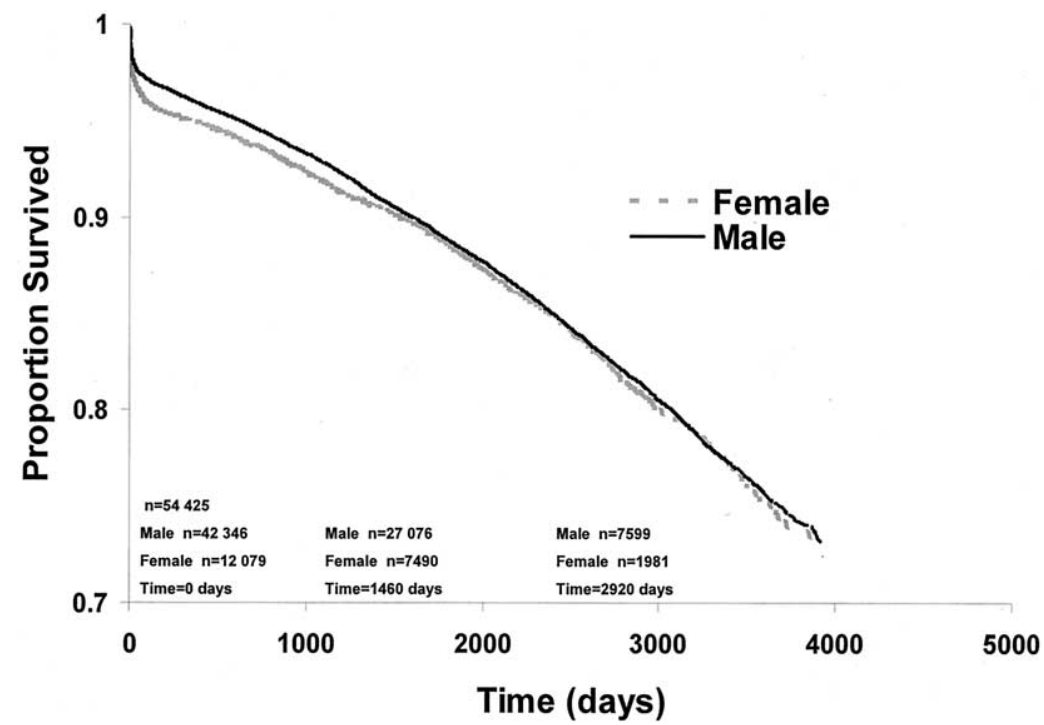

Figure 5. Risk-adjusted survival curve for patients undergoing isolated CABG surgery in Ontario (1991-1999) by sex. The numbers of patients that were available in the cohort to follow are indicated on the graph at the various time points after the operation.

The proportion of women operated on in our cohort was $22 \%$, and this is comparable with population-based US samples, which have ranged between $24 \%$ and $28 \%$. There have been concerns that women compose a minority of surgical patients because fewer are referred for surgical intervention. However, many studies have shown that after their eligibility for an operation is determined through angiography, no female referral bias exists if the analysis includes proper risk adjustment. ${ }^{27-29} \mathrm{We}$ found that the risk-adjusted 30-day mortality improved over the 1990s, likely because of improved surgical techniques for both sexes. This has also been reported by the Northern New England group. ${ }^{16}$ Our observation that early mortality was higher for female patients might have been an artifact of delayed referral or because female patients are older as a result of delayed onset of cardiovascular disease. ${ }^{22}$ It was surprising to observe that female patients persisted to have a higher early mortality in the current era with improved 


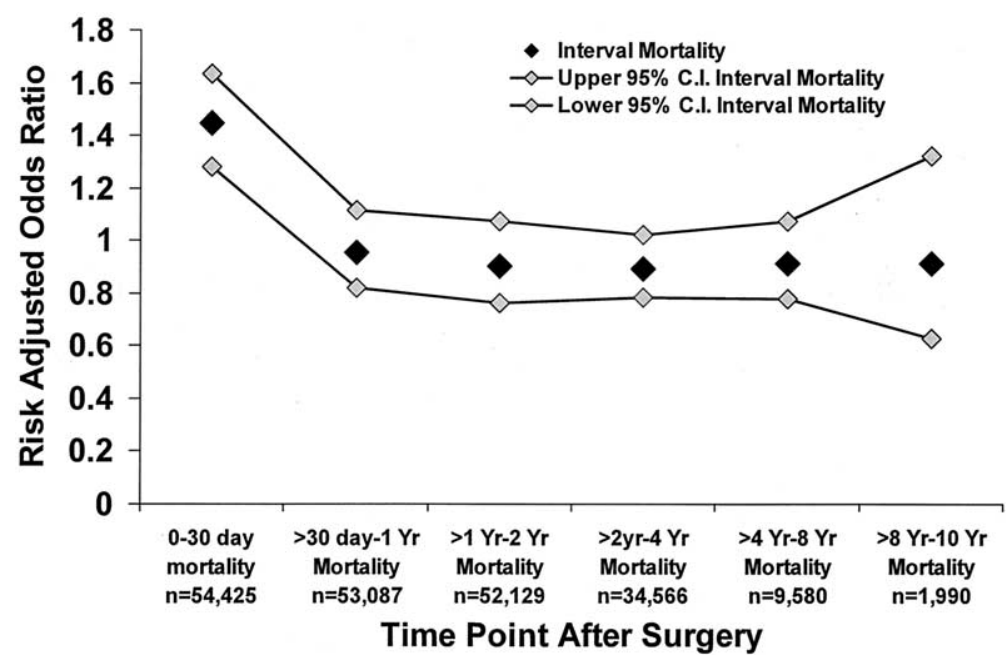

Figure 6. Adjusted ORs and $95 \%$ Cls for mortality among female patients at various time points after isolated CABG surgery in Ontario (1991-1999). The numbers of patients that were available in the cohort to follow at the various time points after the operation are indicated on the graph.

surgical techniques, despite using what is recognized to be comprehensive risk adjustment. ${ }^{24}$

Adjustment models were constructed on subcohorts of patients for whom more data were available to explore this higher early mortality among female patients further. One of these variables, socioeconomic status, a known risk factor for lesser access to cardiac care in Ontario, was used for risk adjustment in the Cox mortality models. ${ }^{30}$ Women were observed to have a significantly lower socioeconomic status than men. Risk adjustment for socioeconomic status on the patients with this information available $(\mathrm{n}=53,702)$ lowered the early 1-year mortality risk (HR decreased from 1.4 to 1.2) for women. We further risk adjusted for BSA on the subcohort with this variable available $(\mathrm{n}=13,921)$ and found women no longer had a higher early mortality risk compared with men. Women tended to have a lower body size, although their distribution of BSA values did overlap with that of men. In view of this fact, the neutralization of early mortality by adjustment with BSA might have occurred partially because BSA served as a surrogate marker for sex. There have been conflicting results in the literature regarding whether a higher early mortality risk for female patients remains after adjusting for BSA.,5,11,15 In summary, a smaller subcohort of our study demonstrates that small BSA appears to explain the higher early mortality risk for female patients. It is evident that this early aspect of female outcomes still requires further investigation, including the evaluation of both biochemical and clinical factors that might help to explain this difference.

In contrast, the risk-adjusted odds for late mortality among female patients appeared equivalent to that of male patients as soon as 1 year after CABG surgery. The previous studies looking at long-term mortality involved post hoc analyses of trials data on patients who were highly selected with discrete inclusion criteria. ${ }^{21,22}$ These studies had patient samples that are not comparable with the older and sicker patients currently referred for CABG surgery. ${ }^{21,22}$ The long-term results of our study are similar to those reported by the Bypass Angioplasty Revascularization Investigation and Coronary Artery Surgery Study trials at 5 to 6 years after surgical intervention. ${ }^{21,22}$ This is surprising considering it still appears that women are higher-risk patients who probably receive fewer arterial grafts with less complete revascularization. In our cohort women were less likely to receive an ITA graft compared with men (70\% of female patients vs $79 \%$ of male patients, $P<.0001$ ). However, when adjustments were made for ITA use, it did not change the early or late mortality risk for female sex. After we adjusted long-term mortality for socioeconomic status, we found that female sex became a significant protective factor (HR, 0.94; 95\% CI, 0.88-1.00; $P=.04$ ).

One of the limitations of our study is that we did not have detailed operative data on factors that might have differed for female patients, including coronary artery size and completeness of revascularization. This type of detailed clinical information could have helped to explain the higher early mortality risk experienced by women. Furthermore, other adverse outcomes, such as nonfatal cardiac events, neurologic complications, or renal insufficiency, might differ significantly after CABG surgery, and we hope to explore these questions in future research.

Our study is unique in using interval mortality in the construction of our regression models rather than cumulative mortality. This approach allowed for tailored assessment with clinical data of those patients who survived to the time interval of interest. Other strengths include the large 
size of our sample, which included the entire population of Ontario patients undergoing CABG and the fact that our study was conducted in the current era, with accurate longterm follow-up.

From our population of patients undergoing $\mathrm{CABG}$, it appears that women might have a persistently higher early mortality in current times but have an excellent late outcome after CABG surgery. In fact, after further adjustment for socioeconomic status, female sex might be a protective factor for long-term survival. Although the long-term benefits of CABG surgery in women are clear, further study is needed to explore ways to reduce mortality in the perioperative period and during the first year after the operation, particularly in the patients at highest risk, such as those with the lowest socioeconomic status.

We thank Yanyan Gong for programming support in linkage of data. We thank the regional care coordinators of the Provincial Cardiac Care Network (CCN) of Ontario for collecting the clinical data used for this study and the Canadian Institutes of Health Research (CIHR) for providing fellowship salary support. We also acknowledge the Tanna Schulich scholarship, which was provided by Sunnybrook and Women's College Health Sciences Centre as funding support for research regarding the impact of gender on cardiac surgery.

\section{References}

1. Fisher LD, Kennedy JW, Davis KB, et al. Association of sex, physical size, and operative mortality after coronary artery bypass in the Coronary Artery Surgery Study (CASS). J Thorac Cardiovasc Surg. 1982;84(3):334-41.

2. O'Connor GT, Morton JR, Diehl MJ, et al. Differences between men and women in hospital mortality associated with coronary artery bypass graft surgery. The Northern New England Cardiovascular Disease Study Group. Circulation. 1993;88(5):2104-10.

3. Zitser-Gurevich Y, Simchen E, Galai N, Mandel M. Effect of perioperative complications on excess mortality among women after coronary artery bypass: the Israeli Coronary Artery Bypass Graft Study (ISCAB). J Thorac Cardiovasc Surg. 2002;123(3):517-24.

4. Aldea GS, Gaudiani JM, Shapira OM, et al. Effect of gender on postoperative outcomes and hospital stays after coronary artery bypass grafting. Ann Thorac Surg. 1999;67(4):1097-103.

5. Edwards FH, Carey JS, Grover FL, Bero JW, Hartz RS. Impact of gender on coronary bypass operative mortality. Ann Thorac Surg. 1998;66(1):125-31.

6. Mickleborough LL, Takagi Y, Maruyama H, Sun Z, Mohamed S. Is sex a factor in determining operative risk for aortocoronary bypass graft surgery? Circulation. 1995;92(suppl 9):II80-4.

7. Abramov D, Tamariz MG, Sever JY, et al. The influence of gender on the outcome of coronary artery bypass surgery. Ann Thorac Surg. 2000;70(3):800-6.

8. Khan SS, Nessim S, Gray R, Czer LS, Chaux A, Matloff J. Increased mortality of women in coronary artery bypass surgery: evidence for referral bias. Ann Intern Med. 1990;112(8):561-7.

9. Woods SE, Noble G, Smith JM, Hasselfeld K. The influence of gender in patients undergoing coronary artery bypass graft surgery: an eightyear prospective hospitalized cohort study. J Am Coll Surg. 2003; 196(3):428-34.

10. Brandrup-Wognsen G, Berggren H, Hartford M, Hjalmarson A, Karlsson T, Herlitz J. Female sex is associated with increased mortality and morbidity early, but not late, after coronary artery bypass grafting. Eur Heart J. 1996;17(9):1426-31.

11. Christakis GT, Weisel RD, Buth KJ, et al. Is body size the cause for poor outcomes of coronary artery bypass operations in women? J Thorac Cardiovasc Surg. 1995;110(5):1344-58.

12. Douglas JS Jr, King SB 3rd, Jones EL, Craver JM, Bradford JM, Hatcher CR Jr. Reduced efficacy of coronary bypass surgery in women. Circulation. 1981;64(suppl):II11-6.

13. Gardner TJ, Horneffer PJ, Gott VL, et al. Coronary artery bypass grafting in women. A ten-year perspective. Ann Surg. 1985;201(6):780-4.

14. Weintraub WS, Clements SD Jr, Crisco LV, et al. Twenty-year survival after coronary artery surgery: an institutional perspective from Emory University. Circulation. 2003;107(9):1271-7.

15. Hammar N, Sandberg E, Larsen FF, Ivert T. Comparison of early and late mortality in men and women after isolated coronary artery bypass graft surgery in Stockholm, Sweden, 1980 to 1989. J Am Coll Cardiol. 1997;29(3):659-64

16. O'Rourke DJ, Malenka DJ, Olmstead EM, et al. Improved in-hospital mortality in women undergoing coronary artery bypass grafting. Northern New England Cardiovascular Disease Study Group. Ann Thorac Surg. 2001;71(2):507-11.

17. Weintraub WS, Wenger NK, Jones EL, Craver JM, Guyton RA. Changing clinical characteristics of coronary surgery patients. Differences between men and women. Circulation. 1993;88(suppl):II79-86.

18. Weintraub WS, Kosinski AS, Wenger NK. Is there a bias against performing coronary revascularization in women? Am J Cardiol. 1996; 78(10):1154-60.

19. Vaccarino V, Abramson JL, Veledar E, Weintraub WS. Sex differences in hospital mortality after coronary artery bypass surgery: evidence for a higher mortality in younger women. Circulation. 2002;105(10):1176-81.

20. Tan ES, van der Meer J, Jan de Kam P, et al. Worse clinical outcome but similar graft patency in women versus men one year after coronary artery bypass graft surgery owing to an excess of exposed risk factors in women. CABADAS. Research Group of the Interuniversity Cardiology Institute of The Netherlands. Coronary Artery Bypass graft occlusion by Aspirin, Dipyridamole and Acenocoumarol/phenoprocoumon Study. J Am Coll Cardiol. 1999;34(6):1760-8.

21. Eaker ED, Kronmal R, Kennedy JW, Davis K. Comparison of the long-term, postsurgical survival of women and men in the Coronary Artery Surgery Study (CASS). Am Heart J. 1989;117(1):71-81.

22. Jacobs AK, Kelsey SF, Brooks MM, et al. Better outcome for women compared with men undergoing coronary revascularization: a report from the bypass angioplasty revascularization investigation (BARI). Circulation. 1998;98(13):1279-85.

23. Herlitz J, Wognsen GB, Karlson BW, et al. Mortality, mode of death and risk indicators for death during 5 years after coronary artery bypass grafting among patients with and without a history of diabetes mellitus. Coron Artery Dis. 2000;11(4):339-46.

24. Tu JV, Sykora K, Naylor CD. Assessing the outcomes of coronary artery bypass graft surgery: how many risk factors are enough? Steering Committee of the Cardiac Care Network of Ontario. J Am Coll Cardiol. 1997;30(5):1317-23.

25. Ivanov J, Tu JV, Naylor CD. Ready-made, recalibrated, or Remodeled? Issues in the use of risk indexes for assessing mortality after coronary artery bypass graft surgery. Circulation. 1999;99(16):2098-104.

26. Deyo RA, Cherkin DC, Ciol MA. Adapting a clinical comorbidity index for use with ICD-9-CM administrative databases. J Clin Epidemiol. 1992;45(6):613-9.

27. Roeters van Lennep JE, Zwinderman AH, Roeters van Lennep HW, et al. Gender differences in diagnosis and treatment of coronary artery disease from 1981 to 1997. No evidence for the Yentl syndrome. Eur Heart J. 2000;21(11):911-8.

28. Ghali WA, Faris PD, Galbraith PD, et al. Sex differences in access to coronary revascularization after cardiac catheterization: importance of detailed clinical data. Ann Intern Med. 2002;136(10):723-32.

29. Miller TD, Roger VL, Hodge DO, Hopfenspirger MR, Bailey KR, Gibbons RJ. Gender differences and temporal trends in clinical characteristics, stress test results and use of invasive procedures in patients undergoing evaluation for coronary artery disease. $\mathrm{J} \mathrm{Am} \mathrm{Coll} \mathrm{Cardiol.}$ 2001;38(3):690-7.

30. Alter DA, Naylor CD, Austin P, Tu JV. Effects of socioeconomic status on access to invasive cardiac procedures and on mortality after acute myocardial infarction. $N$ Engl J Med. 1999;341(18):1359-67. 